\title{
Compressive Strength and Bulk Density of Concrete Hollow Blocks (CHB) Infused with Low-Density Polyethylene (LDPE) Pellets
}

\author{
Alvin Joseph S. Dolores ${ }^{\mathrm{a}}$, Jonathan David D. Lasco ${ }^{\mathrm{b}}$, Timothy M. Bertiz ${ }^{\mathrm{a}}$, \\ Kimjay M. Lamar ${ }^{\mathrm{c}}$ \\ ${ }^{a}$ Department of Civil Engineering, University of the Philippines Los Baños, Laguna 4031, Philippines. \\ ${ }^{b}$ Department of Civil and Environmental Engineering, Texas A\&M University, College Station, Texas, United States.
}

${ }^{c}$ Department of Transportation-Philippine Railways Institute, Philippines.

Received 16 June 2020; Accepted 04 September 2020

\begin{abstract}
Infusing plastic waste to concrete and masonry structures is an increasingly common industry practice that has the potential to create an environment-friendly material that can improve some of the material's properties, craft a novel means to repurpose plastic waste, and reduce the need for mining aggregates in the environment. This concept has been studied extensively in different forms of concrete, as shown by several studies; however, there is a dearth of studies focusing on the incorporation plastic waste in Concrete Hollow Blocks (CHB). In this study, we aim to fill that gap by investigating on the effects of incorporating Low-Density Polyethylene (LDPE), a commonly used plastic material, to CHB on its compressive strength and bulk density. Samples of varying percentages of LDPE replacement by volume $(0$, $10,20,30$ and 40\%) were fabricated and tested. Results showed a general trend of decreasing compressive strength and bulk density upon increasing the amount of LDPE pellets in CHB, which was also observed in previous studies. However, the compressive strength of CHB increased at 10\% LDPE replacement, a result similar to a previous study. It was inferred that the strength of the plastic material could have a direct contribution to the compressive strength of CHB at low percentage of aggregate replacement. Statistical analysis showed that the mix with 10\% LDPE pellets as replacement to sand was the best among the samples tested. It was shown that CHB infused with LDPE pellets has a higher compressive strength than what is normally used in the Philippines. It was concluded that based on compressive strength and bulk density, LDPE pellets is a viable material to use as partial replacement to sand in non-load bearing CHB.
\end{abstract}

Keywords: Low Density Polyethylene; Compressive Strength; Bulk Density; Concrete Hollow Block.

\section{Introduction}

Waste generation is one of the major problems around the world. Factors such as population growth and socioeconomic growth affect the production of waste [1]. In East Asia and the Pacific, the average urban per-capita waste generation is $0.95 \mathrm{~kg} /$ day. Moreover, the per capita waste generation is directly proportional to the area's level of income [2]. Among all types of wastes, plastic is one of the most generated worldwide. This commonly used material comprised approximately 10 percent of the total waste generated globally [2, 3]. Due to its non-biodegradable nature, plastic wastes accumulate either in landfills or on the environment [4]. In 2010, between 4.8 and 12.7 million metric

* Corresponding author: asdolores@up.edu.ph 
tons of plastic wastes produced in coastal countries entered the ocean [3]. To make matters worse, only nine percent of plastic waste is recycled, while about 79 percent is accumulated to landfills and the natural environment [4].

In the Philippines, waste management is still a major issue even with the enactment of Republic Act 9003, also known as the Ecological Solid Waste Management Act of 2000 [5]. Although this law has been passed for several years now, it is yet to be fully implemented [6]. Due to this, problems with waste disposal continue to rise in the country. The local government units only have a collection rate of 40-85 percent of the total waste generated, which is valued at 35,580 tons per day. This means that 15-60 percent of wastes from each of the local governments end up being improperly disposed [7].

Aside from ineffective policy enforcement, the mass production and the dependence of the country to disposable plastics contributes to the growing problem of solid waste management. Due to the economic status in the Philippines, most households choose to buy goods in small quantities which are usually in small plastic packaging, leading to the proliferation of the so-called sachet economy [8]. About 164 million pieces of sachets and 94 million pieces of plastic bags are used in the country per day [9]. As a result, the Philippines is the third-largest source of plastic in the ocean [3].

As such, there is a need to find other means to dispose of plastic wastes. One possible avenue is in the construction industry, particularly infusing plastic wastes of different forms into concrete and mortar. Doing such could yield positive impacts in the environment. Aside from reducing wastes, using plastics as partial replacement for aggregates could potentially reduce the use of sand and gravel - two of the most extracted minerals in the world. In 2018, for example, about USD 360 billion worth of these aggregates were consumed by the global construction industry [10].

The introduction of plastic wastes into asphalt concrete has been widely researched. Several studies proved the effectiveness of plastic wastes as binding materials for asphalt mixture [11-13]. Moreover, several studies attempted to incorporate plastic into concrete. The effects of polymeric wastes to concrete properties were investigated, and it was proven that the presence of plastic waste on concrete could stop the propagation of microcracks, making it a feasible material in low-cost concrete production $[14,15]$.

Moreover, recent studies have shown the effect of incorporating plastic waste to the mechanical properties of concrete. A decreasing trend in mechanical properties with increasing amount of plastic was generally observed across different research [16-18]. However, an increase in compressive, split tensile, and flexural strengths were observed at lower amounts of plastic replacement. Compressive strength increased at around 3-5 percent plastic aggregate, while a split tensile and flexural strengths higher than the control were observed up to 20 and 15 percent plastic aggregate, respectively $[19,20]$. It was also observed that the shape of plastic waste induced also has effects on the strength of concrete [21].

Despite the increasing studies on plastic-infused concrete, there is a dearth of studies concerning masonry units such as concrete hollow blocks (CHB) - a mortar structure still widely used around the world. In the Philippines there is a recent trend of incorporating plastic waste - a lightweight and durable material, in concrete hollow blocks (CHB). $\mathrm{CHB}$ is commonly used as a non-load bearing material, which is an element of the structure that is assumed to be completely detached from the primary structural system of an infrastructure [22]. Plastic-infused CHB has been introduced to the Philippines' construction scene through commercial and government initiatives [23]. For example, Green Antz Builders is a company that focuses on creating ecobricks infused with laminates from plastic wastes as a stronger, cost-effective, and environment-friendly alternative to traditional CHB [24]. On the other hand, the municipal government of Teresa, Rizal, Philippines has employed a system of infusing plastic wastes to traditional CHB in their materials recovery facility [25].

Since CHBs are used as non-load bearing elements in a structure, it could be desirable to reduce the weight of the material at a certain minimum compressive strength. Although incorporating different types of plastic wastes in CHB is already being done, the practice has not been extensively tested and documented in published journals. In one study that does so, the effect of using polypropylene pellets (PP) as partial replacement for sand on the compressive strength and bulk density of CHB [26]. The authors of this study observed that the bulk density of CHB decreases with increasing PP replacement. On the other hand, the compressive strength peaked at $10 \%$ PP replacement.

Aside from polypropylene, another material which can be explored as partial aggregate replacement in concrete is polyethylene, which is the most produced type of plastic in the world [4]. Included in this type of plastic is low-density polyethylene (LDPE), which is primarily used in packaging materials and plastic bags. Subsequently, this material exhibits excellent resistance to shock, moisture, and abrasion [27, 28]. LDPE is also a highly ductile material, as it may be extruded 40 times without causing any significant change in time-dependent mechanical properties, including creep [29]. Its specific gravity ranges from 0.91 to 0.93 [30], which is lighter compared to the typical aggregates used in mortar production, thus has the potential to create a lightweight $\mathrm{CHB}$. 
This study builds on the previous research by Lasco et al. [26] by investigating the feasibility of incorporating pelletized LDPE into the widely-used CHB. This innovation may provide an environment-friendly, novel means to repurpose plastic wastes in the Philippines while improving the properties of the material. As such, the goal of this study is to investigate the effects of incorporating LDPE pellets as a replacement for sand on the compressive strength and bulk density of CHB. Specifically, it aims to:

- Determine the compressive strength and bulk density of CHB with varying levels of LDPE pellets as a partial replacement for sand;

- Analyze the trend in the compressive strength and bulk density of CHB as the concentration of LDPE pellets increases; and

- Select the optimum percent replacement of LDPE pellets.

Through the innovative means of plastic waste disposal suggested in this paper, this study is significant because it offers a way to ameliorate environmental problems due to excessive plastic waste. Furthermore, the study also serves as a springboard for future studies on the concept of incorporating plastic waste to concrete and masonry structures.

This paper is organized as follows. In section 2, the materials used in the study as well as the methodology is discussed. In section 3, the results of the study are shown and explained. Furthermore, the real-world implications of the findings are also discussed. Finally, the article ends with a summary and conclusion, in section 4.

\section{Materials and Methods}

\subsection{Materials and Equipment}

The following were the main materials used in the study: water, Type I Portland cement, white sand, and LDPE pellets. The clean tap water was obtained from the Department of Civil Engineering Laboratory, University of the Philippines Los Baños (UPLB) and was assumed to follow the standards set by the American Society for Testing and Materials (ASTM) C1602 [31]. Cement and white sand were acquired from a local hardware in Los Baños, Laguna. The LDPE pellets shown in Figure 1were acquired from a manufacturer in Valenzuela City, Metro Manila. The size of the pellets used in the concrete mix was limited to a maximum of $4.75 \mathrm{~mm}$.

Moreover, the study utilized the following equipment: concrete mixer, universal testing machine, concrete hollow block molder, and mechanical sieving machine. All the machines used were located at the Department of Civil Engineering Laboratory, UPLB.

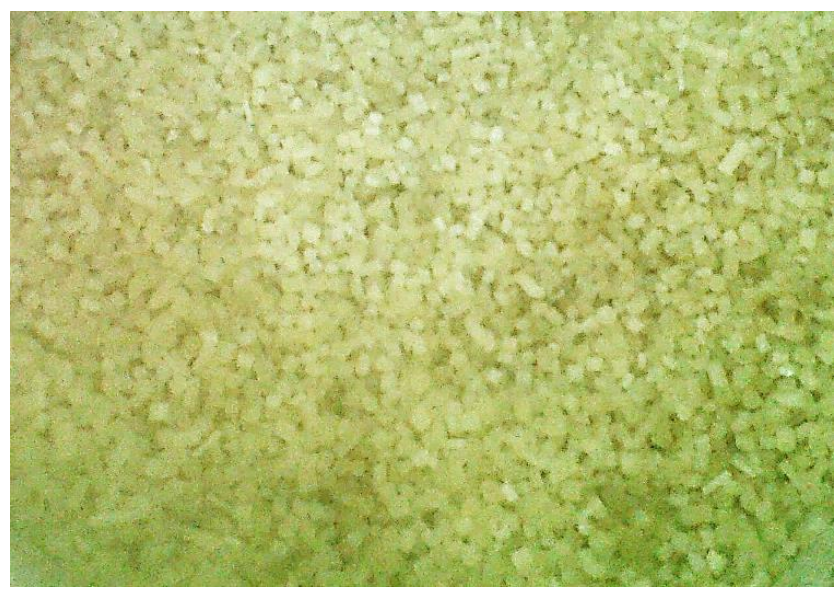

Figure 1. Low-density polyethylene (LDPE) pellets used in the study

\subsection{Methods}

The research design of this study was derived from the research by Lasco et al. [26], as summarized in Figure 2. Preliminary tests were done to determine the specific gravity of the materials as well as the fineness modulus of sand. The specific gravity of water and cement were assumed to be 1.00 and 3.15 , respectively. On the other hand, the specific gravity of white sand and LDPE pellets were measured through the volume displacement method. Water was used as the base fluid for sand, while kerosene was used for LDPE pellets. The fineness modulus was tested using sieve analysis. 


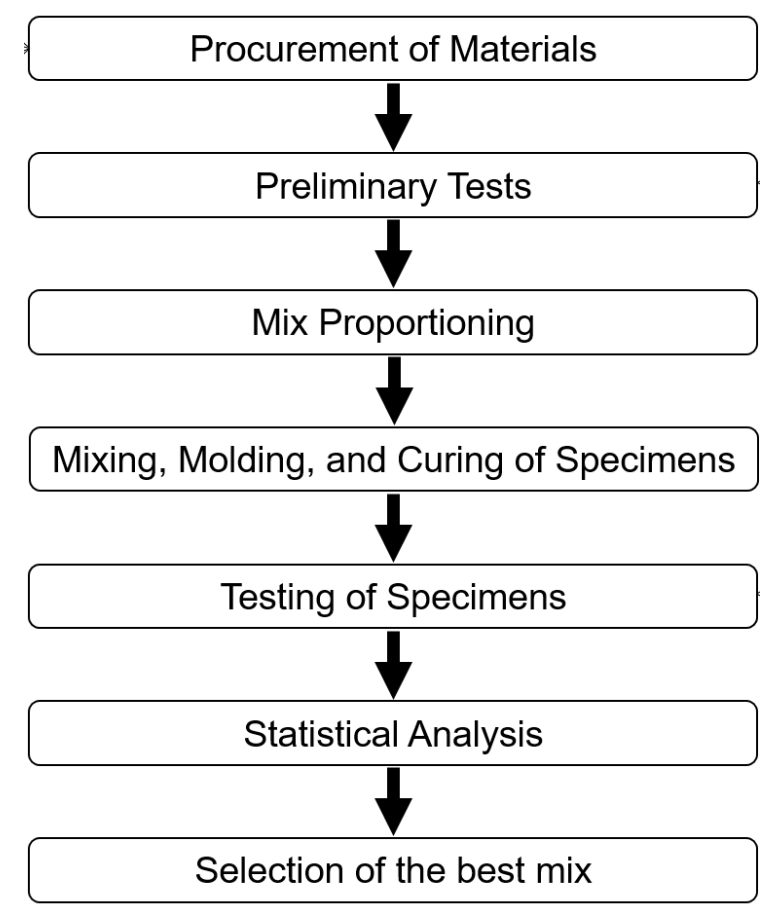

Figure 2. Research Design [26]

Preliminary tests included the determination of specific gravity of the white sand and LDPE pellets using displacement method, and identifying their size distribution using sieve analysis. White sand had a specific gravity of 2.44, while LDPE pellets had 0.90. The white sand used had a fineness modulus of 3.2, with the grading curve shown in Figure 3. The LDPE pellets were uniform in size, as majority of the particles passed through sieve number 4 (4.75 $\mathrm{mm})$, but retained at sieve number $8(2.36 \mathrm{~mm})$.

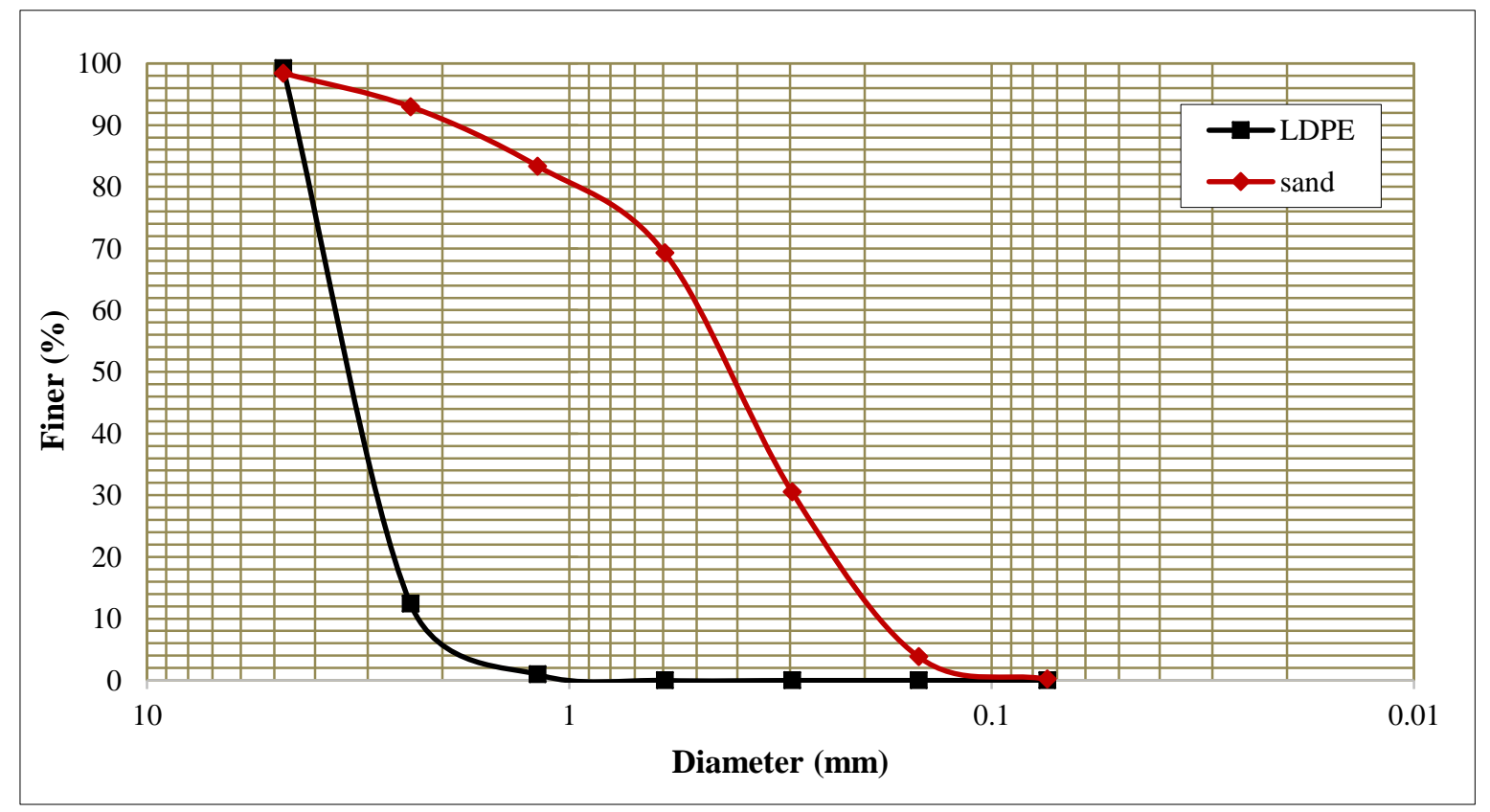

Figure 3. Grading curve of white sand and LDPE

Several mix proportions were computed based on the American Concrete Institute (ACI) Recommended Practice 211.1 [32]. Different amounts of LDPE pellets as sand replacement by volume were considered: $0 \%$ (batch A), $10 \%$ (batch B), 20\% (batch C), 30\% (batch D) and 40\% (batch E). The mix proportions were expressed in terms of mass per unit volume of concrete $\left(\mathrm{kg} / \mathrm{m}^{3}\right)$ as shown in Table 1 . The water-to-cement ratio used was 0.5 , and the cement-tosand ratio used was 1:5 (by volume), respectively. 
Table 1. Concrete mix proportions with different amounts of LDPE pellets as sand replacement

\begin{tabular}{ccccccc}
\hline \multirow{2}{*}{ Material } & \multirow{2}{*}{ Specific Gravity } & \multicolumn{5}{c}{ Mass of Material per Unit Volume of Concrete $\left(\mathbf{k g} / \mathbf{m}^{\mathbf{3}}\right)$} \\
\cline { 3 - 7 } & & $\mathbf{A ~ ( 0 \% )}$ & $\mathbf{B}(\mathbf{1 0 \%})$ & $\mathbf{C ~ ( 2 0 \% )}$ & $\mathbf{D} \mathbf{( 3 0 \% )}$ & $\mathbf{E ~ ( 4 0 \% )}$ \\
\hline Water & 1.00 & 207.92 & 193.71 & 178.47 & 162.07 & 144.39 \\
Sand & 2.44 & 1610.56 & 1500.51 & 1382.44 & 1255.42 & 1118.41 \\
Cement & 3.15 & 415.84 & 387.43 & 356.94 & 324.15 & 288.77 \\
LDPE & 0.90 & 0 & 61.50 & 127.48 & 198.46 & 275.02 \\
\hline
\end{tabular}

Eight specimens of three-cell CHB with a length of 16 in., a width of 4 in., and a height of 8 in. were fabricated for each percentage of LDPE replacement using the CHB molder shown in Figure 4. After molding, the specimens were transferred into a safe site for curing and monitoring. The curing period for the concrete hollow blocks was 28 days. The curing method was based on ASTM C140 [33].

The bulk density of three (3) specimens per group were tested using a procedure based on ASTM C127 [34]. Each specimen was weighed in air and water. The specific gravity was computed by dividing the weight of the specimen in air to its weight in water. The volume of each specimen was then computed by dividing its weight to the computed specific gravity. The cross-sectional area of the CHB was computed by dividing volume to its height.

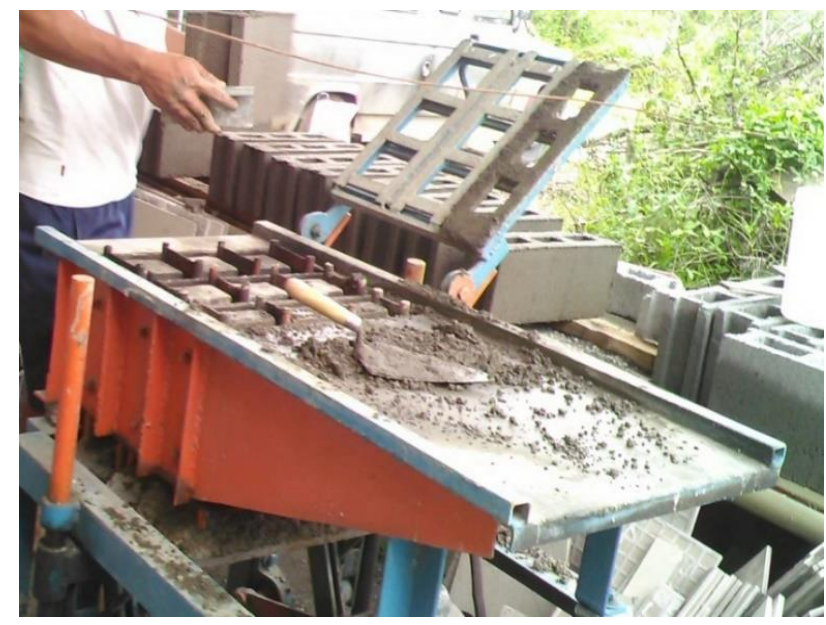

Figure 4. Three-cell CHB molder, $4 \times 8 \times 16$ in.

Five (5) specimens per batch were tested using the Universal Testing Machine. The procedure used for testing the compressive strength of the hollow blocks was based on ASTM C140 [17]. The compressive strength for each specimen was computed using the equation:

$\sigma_{c}=\frac{P_{\text {cap }}}{A_{\text {net }}}$

Where $\sigma_{c}$ is the compressive strength of the specimen, $\mathrm{P}_{\text {cap }}$ is the force applied on the concrete hollow block, and $\mathrm{A}_{\text {net }}$ is the net area of the specimen.

The average values of compressive strength and bulk density per sample group were taken as the representative values. Two statistical tests were done to further evaluate the results. First, the F test using one-way analysis of variance (ANOVA) was used to determine if at least one batch has a significant difference from the control. Second, a pairwise mean comparison using Duncan's multiple range test (DMRT) was used to determine if two batches of specimens have a significant difference from each other. All statistical analyses were done at $95 \%$ level of confidence.

The best mix proportion was selected using the weighted sum model. In this method, all the alternatives were evaluated using the equation:

$A_{j}=\sum_{i=1}^{n} a_{i j} w_{i}$

Where $A_{j}$ was the score of alternative $j, a_{i j}$ was the normalized value of the alternative $j$ in criterion $i$, and $w_{i} w_{a s}$ the weight of importance of criteria $i$. The alternative with the highest score was considered as the best [35]. If an increase in the value of a certain factor was deemed beneficial, then the normalized value for the factor was equal to the 
individual value divided by the maximum value among the alternatives. Otherwise, the normalized value was equal to the minimum value among the alternatives divided by the individual value of the alternative considered. For this study, compressive strength and bulk density were given equal weights.

\section{Results and Discussion}

\subsection{Compressive Strength}

Generally, the compressive strength of the CHB specimens decreased with increasing amounts of LDPE pellets, as shown in Figure 5. This trend is consistent with the results from the previous studies. Ruiz-Herrero et al. observed a decrease in compressive strength in all concrete and mortar samples infused with polyethylene (PE) and polyvinyl chloride (PVC) [36]. Saikia and De Brito also observed the same behavior in concrete with different shapes of polyethylene terephthalate (PET) as partial replacement for the natural aggregates [37]. Safi et al. noted a similar trend upon testing the compressive strength in 3, 7, 14, and 28 days of self-compacting mortar with plastic waste [38]. The comparison of the relative percentage change 28-day compressive strength across different studies is shown in Table 2 .

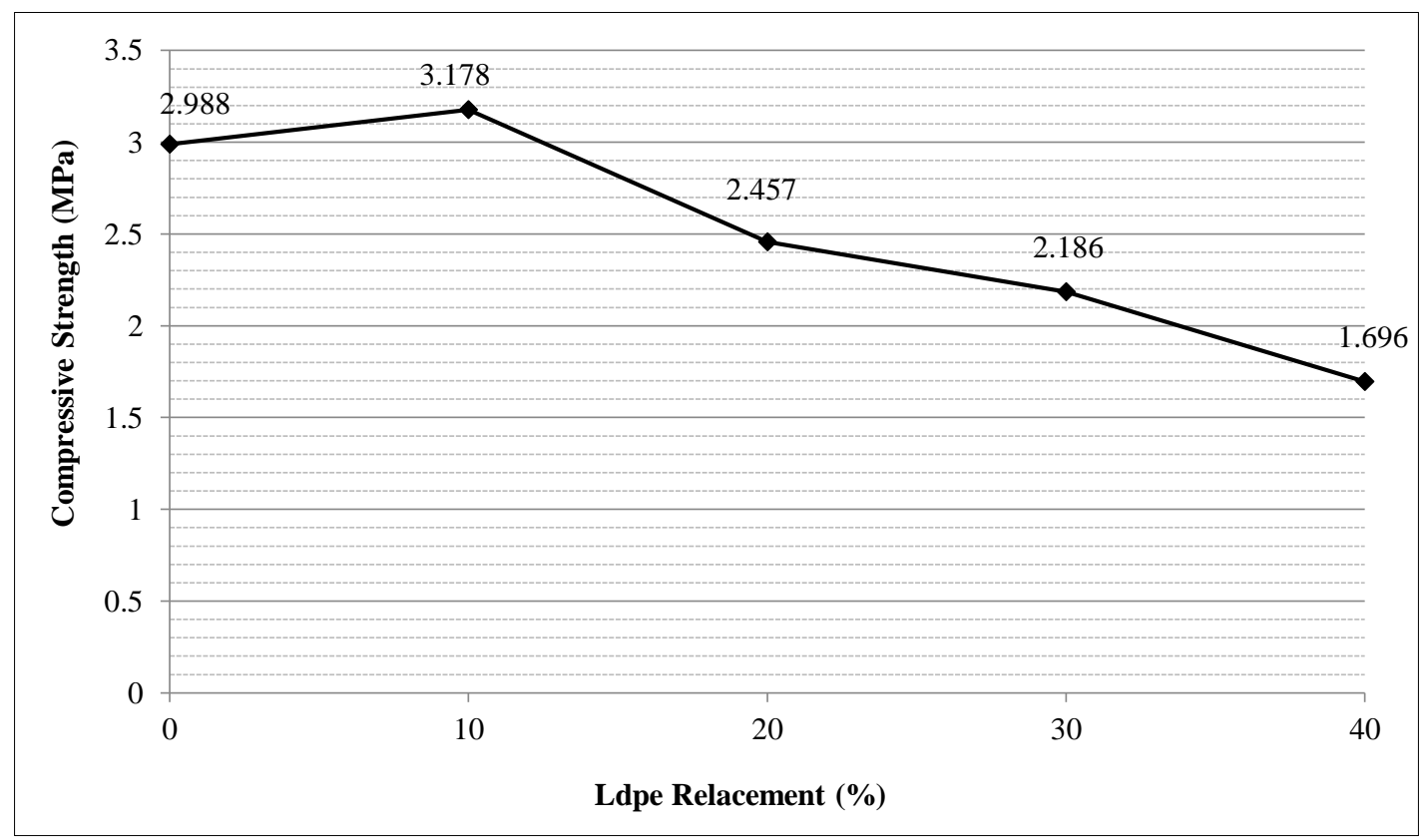

Figure 5. Compressive strength of CHB in with varying levels of LDPE replacement

Table 2. Relative percentage change in compressive strength of concrete and mortar with varying levels of plastic as aggregate replacement

\begin{tabular}{|c|c|c|c|c|c|c|c|c|c|c|c|c|c|}
\hline \multirow{2}{*}{ Plastic used } & \multicolumn{12}{|c|}{ Percentage of plastic aggregate $(\%)$} & \multirow{2}{*}{ References } \\
\hline & 1 & 2.5 & 3 & 5 & 7 & 10 & 15 & 20 & 25 & 30 & 40 & 50 & \\
\hline LDPE (pellets) & - & - & - & - & - & 6 & - & -18 & - & -27 & -43 & - & --- \\
\hline PP (pellets) & - & - & - & - & - & 58 & - & -23 & - & -33 & -54 & - & Lasco et al., 2017 [26] \\
\hline PVC & - & -8 & - & -33 & - & -53 & - & -81 & - & - & - & - & Ruiz-Herrero et al., 2016 [36] \\
\hline $\mathrm{PE}$ & - & -14 & - & -27 & - & -73 & - & -90 & - & - & - & - & Ruiz-Herrero et al., 2016 [36] \\
\hline $\mathrm{PVC}+\mathrm{PE}$ & - & -11 & - & -33 & - & -46 & - & -88 & - & - & - & - & Ruiz-Herrero et al., 2016 [36] \\
\hline PET (coarse) & - & - & - & -9 & - & -14 & -21 & - & - & - & - & - & Saikia \& De Brito, 2014 [37] \\
\hline PET (fine) & - & - & - & -12 & - & -21 & -40 & - & - & - & - & - & Saikia \& De Brito, 2014 [37] \\
\hline PET (pellets) & - & - & - & -28 & - & -44 & -63 & - & - & - & - & - & Saikia \& De Brito, 2014 [47] \\
\hline plastic waste & - & - & - & - & - & -5 & - & -13 & - & -33 & - & -38 & Safi et al., 2013[38] \\
\hline PET & - & - & - & 46 & - & 9 & -11 & -17 & -37 & -46 & - & - & Azhdarpour et al., 2016 [20] \\
\hline PET (cutout) & 1 & - & -17 & -13 & -15 & -19 & - & - & - & - & - & - & Hameed \& Ahmed, 2019 [17] \\
\hline
\end{tabular}

The weakening of specimens with increasing LDPE concentration may be due to the relatively larger size of the pellets compared to sand. Larger aggregates tend to increase the likelihood of the existence of internal weak planes, as well as the stress concentration in the cement paste-aggregate interfaces. Moreover, the probability of the occurrence 
of areas with high LDPE concentration increases as the percentage of replacement increases. A higher concentration of larger aggregates increases the existence of weak regions, thus lowering its compressive strength [39].

The decrease in compressive strength may also be caused by the nature of LDPE as a material, which may have prevented several processes to occur. Plastic is a hydrophobic and impermeable material, which could hinder the hydration between the water and cement during the curing period [15]. Due to the lack of interaction between the cement paste matrix and the plastic aggregate, there is a low level of adhesion between the two components within the CHB. Moreover, the unabsorbed water tends to surround the plastic aggregates, which would create a weaker interfacial transition zone, leading to weaker bonding [24, 37].

Moreover, the smooth surface of LDPE pellets would induce less friction between the plastic and the cement paste matrix. The friction force between materials is dependent on the roughness of the surface [40]. The smooth surface of the pellets would likely lead to slippage within the contact surfaces between LDPE and the cement paste, thus contributing to the lack of adhesion between the two materials.

However, an increase in compressive strength was observed at 10\% LDPE replacement. The increase in compressive strength was also observed in the study by Lasco et al., where PP pellets where used as partial replacement for sand in CHB [26]. At lower concentrations, the pellets may have contributed to the compressive strength of the hollow block. LDPE has a compressive strength of 9-10 MPa [30], which is stronger than the compressive strength of all the specimens without LDPE replacement (Batch A). However, increasing the concentration of replacement could lead to higher probability of creating areas with closely clustered LDPE pellets, which could lead to localized failure [26]. A similar trend of increase in compressive strength at low percentage of plastic aggregates was also observed in the separate studies of Azdharpour et al., and Hameed and Ahmed [17, 20]. The increase in compressive strength could have been caused by the flexible nature of plastic fragments, which allowed the conversion of a portion of shear stress to tensile stress before they were separated from other materials [20].

\subsection{Bulk Density}

Generally, the bulk density of the CHB decreased with increasing amounts of LDPE pellets (Figure 6). One of the factors that affect the properties of composites is the proportion of the matrix and the reinforcement. This statement, otherwise known as the Law of Mixtures, may be further expressed as:

$X_{c}=X_{m} v_{m}+X_{f} v_{f}$

Where $X_{c}$ is the weight of the composite, $X_{m}$ and $v_{m}$ are the weight and volume fractions of the matrix, and $X_{f}$ and $v_{f}$ are the weight the volume fractions of the reinforcement [41].

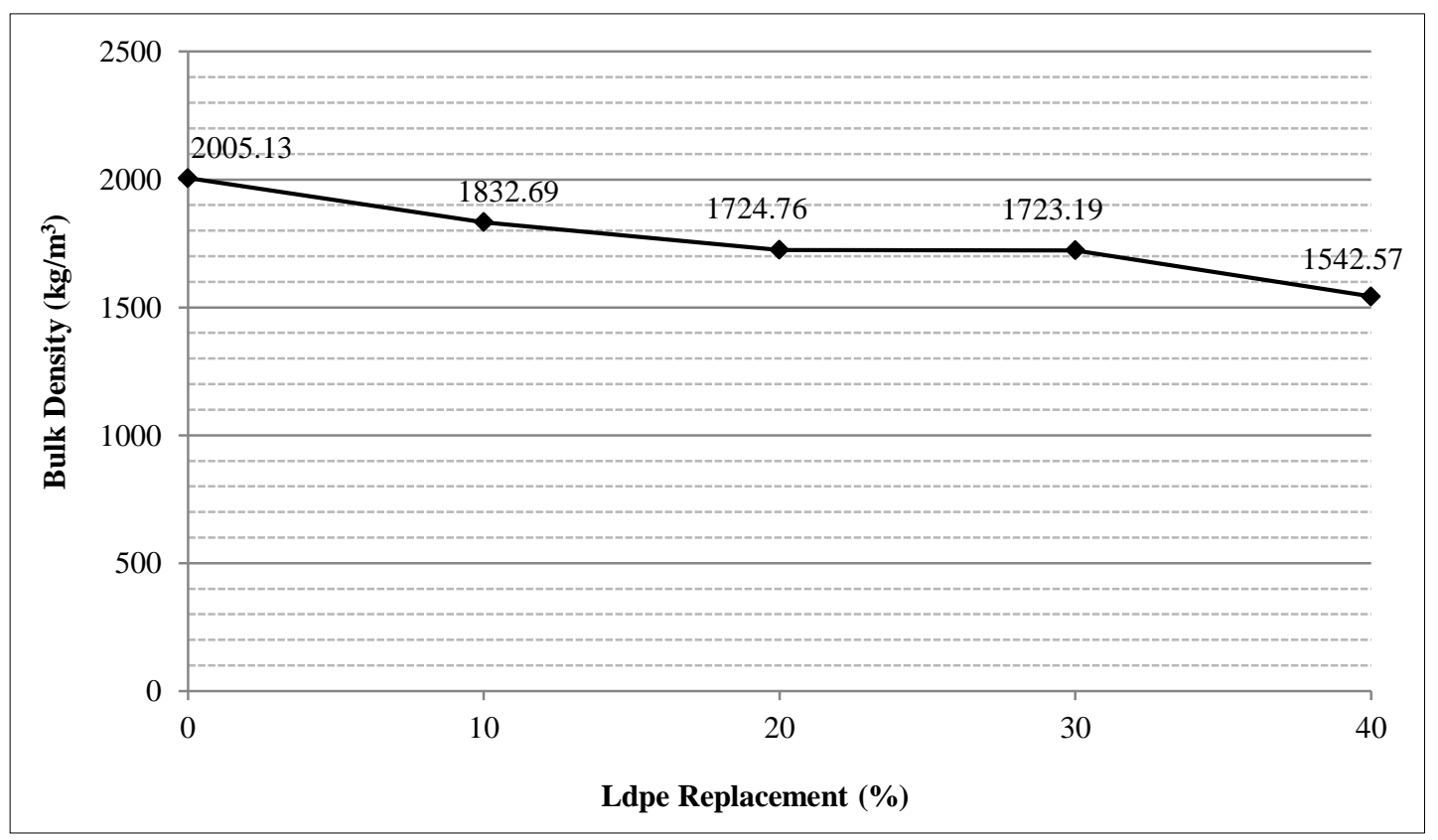

Figure 6. Bulk density of hollow blocks with varying levels of LDPE replacement

Since LDPE pellets ( $\mathrm{SG}=0.90$ ) are the lightest components of the concrete mix, replacing a certain portion of white sand ( $\mathrm{SG}=2.44$ ) with pellets caused the specific gravity of the $\mathrm{CHB}$ to decrease, thus making it lighter. Furthermore, as 
white sand was gradually replaced by LDPE pellets, the amount of cement $(\mathrm{SG}=3.15)$ and water $(\mathrm{SG}=1.0)$ needed in the mixture also decreased since their values are dependent on the amount of sand needed in the mix. Because of this, the bulk density of the CHB decreased even further. This trend is consistent with the findings from other studies, as shown in Table 3.

Table 3. Relative percentage change in compressive strength of concrete and mortar with varying levels of plastic as aggregate replacement

\begin{tabular}{|c|c|c|c|c|c|c|c|c|c|c|c|c|c|}
\hline \multirow{2}{*}{ Plastic used } & \multicolumn{12}{|c|}{ Percentage of plastic aggregate $(\%)$} & \multirow{2}{*}{ Reference } \\
\hline & 1 & 2.5 & 3 & 5 & 7 & 10 & 15 & 20 & 25 & 30 & 40 & $\mathbf{5 0}$ & \\
\hline LDPE (pellets) & - & - & - & - & - & -9 & - & -14 & - & -14 & -23 & - & --- \\
\hline PP (pellets) & - & - & - & - & - & -5 & - & -8 & - & -12 & -17 & - & Lasco et al., 2017 [26] \\
\hline PVC & - & -1 & - & -2 & - & -6 & - & -16 & - & - & - & - & Ruiz-Herrero et al., 2016 [36 \\
\hline $\mathrm{PE}$ & - & -1 & - & -7 & - & -17 & - & -18 & - & - & - & - & Ruiz-Herrero et al., 2016 [36 \\
\hline $\mathrm{PVC}+\mathrm{PE}$ & - & -1 & - & -4 & - & -9 & - & -18 & - & - & - & - & Ruiz-Herrero et al., 2016 [36 \\
\hline PET (coarse) & - & - & - & -3 & - & -5 & -6 & - & - & - & - & - & Saikia \& De Brito, 2014 [37] \\
\hline PET (fine) & - & - & - & -2 & - & -4 & -6 & - & - & - & - & - & Saikia \& De Brito, 2014 [37] \\
\hline PET (pellets) & - & - & - & -2 & - & -4 & -6 & - & - & - & - & - & Saikia \& De Brito, 2014 [47] \\
\hline plastic waste & - & - & - & - & - & -16 & - & -23 & - & -23 & - & -34 & Safi et al., 2013[38] \\
\hline PET & - & - & - & -1 & - & -3 & -5 & -6 & -8 & -8 & - & - & Azhdarpour et al., 2016 [20] \\
\hline PET (cutout) & -1 & - & -1 & -5 & -3 & -7 & - & - & - & - & - & - & Hameed \& Ahmed, $2019[17]$ \\
\hline
\end{tabular}

\subsection{Statistical Analysis}

The F test using one-way ANOVA revealed that at least one of the means is different from the rest, both for compressive strength and bulk density. Thus pairwise mean comparison tests could be done to further determine which pairs of data have significant differences from each other.

Results of pairwise mean comparison for compressive strength using DMRT (Table 4) showed that batches A and $\mathrm{B}$ of the specimens both belong to group A. Therefore, the increase in the compressive strength at $10 \%$ replacement was not significant when compared to the specimens with no LDPE replacement. However, batch B did not belong to the same group as batches $\mathrm{C}, \mathrm{D}$, and $\mathrm{E}$ of the specimens. This showed that the decrease in strength at the succeeding replacement levels $(20,30,40 \%)$ was significant compared to the compressive strength at $10 \%$ replacement.

Table 4. Grouping of batches using DMRT with compressive strength as the response variable

\begin{tabular}{cccc}
\hline Batch & $\begin{array}{c}\text { LDPE Replacement } \\
(\%)\end{array}$ & $\begin{array}{c}\text { Mean Compressive Strength } \\
(\mathbf{M P a})\end{array}$ & Groups \\
\hline $\mathrm{A}$ & 0 & 2.988 & $\mathrm{AB}$ \\
$\mathrm{B}$ & 10 & 3.178 & $\mathrm{~A}$ \\
$\mathrm{C}$ & 20 & 2.457 & $\mathrm{BC}$ \\
$\mathrm{D}$ & 30 & 2.186 & $\mathrm{CD}$ \\
$\mathrm{E}$ & 40 & 1.696 & $\mathrm{D}$ \\
\hline
\end{tabular}

On the other hand, the results of pairwise mean comparison for bulk density (Table 5) showed that all batches were significantly different from each other, except for batches C and D which belonged at the same statistical group C. This revealed that generally, there was a significant decrease in the bulk density as the percentage of LDPE replacement increased.

Table 5. Grouping of batches using DMRT with bulk density as the response variable

\begin{tabular}{cccc}
\hline Batch & $\begin{array}{c}\text { LDPE Replacement } \\
(\boldsymbol{\%})\end{array}$ & $\begin{array}{c}\text { Mean Bulk Density } \\
\left(\mathbf{k g} / \mathbf{m}^{\mathbf{3}}\right)\end{array}$ & Groups \\
\hline A & 0 & 2005.128 & $\mathrm{~A}$ \\
B & 10 & 1832.695 & B \\
C & 20 & 1724.757 & C \\
D & 30 & 1723.189 & C \\
E & 40 & 1542.571 & D \\
\hline
\end{tabular}




\subsection{Selection of the Best Mix}

The computation for the weighted sums (Table 6) showed that batch B obtained the highest performance score among all the specimen groups. Therefore, batch B with 10\% LDPE replacement was selected as the best mix for the study.

An increase in compressive strength with respect to the control was only observed for batch $\mathrm{B}$, which made it the best in terms of the criteria mentioned. On the other hand, although batch E yielded the lowest bulk density, its compressive strength decreased by $43.23 \%$ with respect to the control group. The large decrease in strength outweighed the benefit of low bulk density in terms of usability in construction [41].

Table 6. Result of the weighted sum model for different mix proportions

\begin{tabular}{|c|c|c|c|c|c|c|c|}
\hline \multirow{2}{*}{ Batch } & \multirow{2}{*}{$\begin{array}{c}\text { LDPE } \\
\text { Replacement }(\%)\end{array}$} & \multirow{2}{*}{$\begin{array}{c}\text { Mean Compressive } \\
\text { Strength (MPa) }\end{array}$} & \multirow{2}{*}{$\begin{array}{c}\text { Mean Bulk } \\
\text { Density }\left(\mathrm{kg} / \mathrm{m}^{3}\right)\end{array}$} & \multicolumn{2}{|c|}{ normalized score } & \multirow{2}{*}{$\begin{array}{l}\text { Performance } \\
\text { Score }\end{array}$} & \multirow{2}{*}{ Rank } \\
\hline & & & & $\begin{array}{l}\text { Compressive } \\
\text { Strength }\end{array}$ & Bulk Density & & \\
\hline A & 0 & 2.988 & 2005.128 & 0.940 & 0.769 & 0.855 & 2 \\
\hline $\mathrm{B}$ & 10 & 3.178 & 1832.695 & 1.000 & 0.842 & 0.921 & 1 \\
\hline $\mathrm{C}$ & 20 & 2.457 & 1724.757 & 0.773 & 0.894 & 0.834 & 3 \\
\hline $\mathrm{D}$ & 30 & 2.186 & 1723.189 & 0.688 & 0.895 & 0.792 & 4 \\
\hline $\mathrm{E}$ & 40 & 1.696 & 1542.571 & 0.534 & 1.000 & 0.767 & 5 \\
\hline
\end{tabular}

\subsection{Comparison to the Previous Study on CHB and to Existing Standards}

The results of this study can be compared directly with the research done by Lasco et al., which used PP pellets as partial replacement for sand in CHB [26]. The results of the compressive strength and bulk density is shown in Table 7.

Table 7. Relative percentage change of compressive strength and bulk density of CHB with LDPE and PP pellets as partial replacement for sand

\begin{tabular}{|c|c|c|c|c|c|c|c|c|}
\hline \multirow{3}{*}{$\begin{array}{l}\text { Aggregate } \\
\text { Replacement } \\
(\%)\end{array}$} & \multicolumn{4}{|c|}{ Compressive Strength } & \multicolumn{4}{|c|}{ Bulk Density } \\
\hline & \multicolumn{2}{|c|}{ LDPE pellets } & \multicolumn{2}{|c|}{ PP pellets } & \multicolumn{2}{|c|}{ LDPE pellets } & \multicolumn{2}{|c|}{ PP pellets } \\
\hline & MPa & $\%$ change & MPa & $\%$ change & $\mathrm{kg} / \mathrm{m}^{3}$ & $\%$ change & $\mathrm{kg} / \mathrm{m}^{3}$ & $\%$ change \\
\hline 0 & 2.988 & & 2.26 & & 2005.13 & & 2028 & \\
\hline 10 & 3.178 & 6.36 & 3.58 & 58.41 & 1832.69 & -8.60 & 1930.67 & -4.80 \\
\hline 20 & 2.457 & -17.77 & 1.73 & -23.45 & 1724.76 & -13.98 & 1865 & -8.04 \\
\hline 30 & 2.186 & -26.84 & 1.52 & -32.74 & 1723.19 & -14.06 & 1785.33 & -11.97 \\
\hline 40 & 1.696 & -43.24 & 1.05 & -53.54 & 1542.57 & -23.07 & 1690 & -16.67 \\
\hline
\end{tabular}

Both studies yielded similar results: the specimens with 10 percent aggregate replacement was considered as the best mix among all the groups. In both occasions, the specimens exhibited the highest compressive strength and a decrease in bulk density.

While the trends for compressive strength and bulk density are similar for both studies, it is notable that CHB with PP pellets had a higher positive relative change in compressive strength at 10 percent aggregate replacement. The higher spike in compressive strength observed in concrete could be a direct result of the contribution of PP pellets to the compressive strength of CHB. As a material, PP has a compressive strength of about $34 \mathrm{MPa}$ [42], which is over three times higher compared to LDPE. As such, the type of plastic used as aggregate replacement can have a direct effect to the compressive strength of concrete.

A non-load bearing material like CHB would benefit on increased compressive strength and decreased bulk density. As such, the results of the study shall be compared to ASTM c129, which is the standard for non-loadbearing masonry units [43]. The standard states that the minimum compressive strength required which is about $4.1 \mathrm{MPa}$. Still, the strength of the CHB in all the specimen groups tested were higher compared to the commercially available CHB in the Philippines, which only has a compressive strength of about 1.0 MPa [24, 44]. The best mix concrete (10\% LDPE replacement) recorded a strength three times higher than the typical strength of commercially available CHB.

In terms of weight standards set by ASTM c129 [43], the best mix concrete fell under medium-weight concrete. Specimens at 20 and 30 percent replacements were also classified as medium-weight concrete, while the control $(0 \%$ replacement) was classified as normal weight. Of all the specimen groups, only the CHB at 40 percent replacement 
was classified as lightweight concrete. In contrast, commercially available CHB in the Philippines weighs about 1600 $\mathrm{kg} / \mathrm{m} 3$, which is considered as lightweight concrete [43, 44]. There are no default requirements for concrete weight as per ASTM c129.

Given the specifications, CHB with LDPE replacement showed improved specifications in terms of its compressive strength compared to its commercially available counterparts. As such, LDPE-infused CHB can be a viable replacement to the commercial CHB in the Philippines for non-load bearing elements in the structures.

\section{Summary and Conclusions}

Plastic is one of the highest generated wastes globally. Due to its non-biodegradable nature and the lack of effective disposal methods, this material has damaged ecosystems, from land to the oceans. As such, there is a need to find an effective way to dispose of plastics without causing harm to the environment. In the Philippines, one potential outlet for plastic wastes is in concrete. As a lightweight material, plastic has the potential to decrease the specific gravity of concrete if used as a partial replacement to the aggregates, as confirmed by several studies. In the Philippines, plastic waste has been used as partial aggregate replacement for CHB, a non-load bearing material commonly used in construction. However, the application of plastic to CHB has yet to be studied extensively.

The study, building on the work of Lasco et al. [26], aimed to test the viability of using plastics as an aggregate replacement into CHB. In this study, LDPE, the same plastic type used in plastic bags and packaging materials, was infused to CHB to partially replace sand. As such, the study aimed to investigate the effects of Incorporating LowDensity Polypropylene (LDPE) pellets as a replacement for sand on the compressive strength and bulk density of CHB. First, the compressive strength and bulk density of CHB at various levels of LDPE replacement were determined. Second, the trend of changes in compressive strength and bulk density were analyzed. Finally, through statistical analysis, the specimens were evaluated using weighted sum model and the best among the groups was selected.

The results showed that as the percentage of LDPE replacement increased, both the compressive strength and the bulk density of CHB decreased. Therefore, the percentage replacement of LDPE pellets is, in general, inversely proportional to the compressive strength and bulk density of CHB. Both of these trends were also observed in other studies that added plastic of different forms and types to the concrete mix.

However, an increase in compressive strength was observed at 10\% replacement of LDPE pellets. No further increase manifested at higher proportions of LDPE replacement. The increase in compressive strength at small percentage of aggregate replacement was observed in similar studies. Hence, it was concluded that replacing sand with LDPE pellets up to $10 \%$ (by volume) will increase the compressive strength. Specimens with successive replacement percentages of LDPE pellets did not show significant difference in terms of compressive strength. On the other hand, the difference in bulk density among the specimen was mostly significant across different groups. Thus, it was concluded that the mix proportion with 10\% LDPE replacement is the best alternative if the compressive strength and bulk density of CHB are of equal importance.

The results and the selection of best mix were consistent with the previous study which used PP pellets as partial aggregate replacement. While the trend of the results was the same between the two, it was observed that the CHB with PP pellets from the previous study had a higher relative increase in compressive strength at 10 percent replacement compared to the CHB with LDPE pellets. The difference in relative change was attributed to the compressive strength of the two materials, which had a direct effect in the compressive strength of CHB. As a material, PP has a compressive strength of about $34 \mathrm{MPa}$, which is about three times higher than the strength of LDPE (9-10 MPa). When the results of the study were compared to the standards set by ASTM c129, it was found out that no group of specimens reached the minimum required strength in non-load bearing masonry unit, which is about 4.1 MPa. However, all groups have a higher compressive strength compared to the commercially available CHB in the Philippines, which has a compressive strength of $1 \mathrm{MPa}$. As such, the CHB infused with LDPE pellets can be considered as a better product in terms of its compressive strength rather than the commercially available CHB.

Based on these findings, it can be concluded that LDPE pellets is a viable material to use as partial replacement for sand in non-load bearing CHB, especially in the Philippine market. Infusing LDPE to CHB in small percentage can make the material stronger and lighter. Moreover, the findings of the study showed that infusing LDPE pellets into CHB can be beneficial to the environment: it can provide an avenue for repurposing plastic waste which were typically accumulating in the environment, and it can reduce the need for mining aggregate materials

\section{Acknowledgements}

The authors thank the Department of Civil Engineering, University of the Philippines Los Baños for allowing the use of the laboratory to conduct the study. Likewise, the authors express their gratitude to Engr. Ernesto Cristobal, Ms. Celeth Kylle Gregorio and Ms. Cyrille Eliz Gregorio for assisting in the completion of the study. 


\section{Conflicts of Interest}

The authors declare no conflict of interest.

\section{References}

[1] Darban Astane, A. R., and M. Hajilo. "Factors affecting the rural domestic waste generation." Global Journal of Environmental Science and Management 3, no. 4 (2017): 417-426. doi:10.22034/gjesm.2017.03.04.007.

[2] Hoornweg, D., \& Bhada-Tata, P. "WHAT A WASTE: A Global Review of Solid Waste Management. Urban Development \& Local Government Unit.” (2012).

[3] Jambeck, J. R., R. Geyer, C. Wilcox, T. R. Siegler, M. Perryman, A. Andrady, R. Narayan, and K. L. Law. "Plastic Waste Inputs from Land into the Ocean.” Science 347, no. 6223 (February 12, 2015): 768-771. doi:10.1126/science.1260352.

[4] Geyer, Roland, Jenna R. Jambeck, and Kara Lavender Law. "Production, Use, and Fate of All Plastics Ever Made." Science Advances 3, no. 7 (July 2017): e1700782. doi:10.1126/sciadv.1700782.

[5] Republic Act 9003. "Ecological Solid Waste Management Act of 2000”. Congress of the Philippines (2000). Enacted January $26,2001$.

[6] Bernardo, Eileen C. "Solid-Waste Management Practices of Households in Manila, Philippines." Annals of the New York Academy of Sciences 1140, no. 1 (October 2008): 420-424. doi:10.1196/annals.1454.016.

[7] Castillo, A., \& Otoma, S. "Status of Solid Waste Management in the Philippines." Annual Conference of Japan Society of Material Cycles and Waste Management (2013): 677-678. doi:10.14912/jsmcwm.24.0_677.

[8] Liamzon, C., Benosa, S., Aliño, M., \& Baconguis, B. “SACHET ECONOMY: Big Problems in Small Packets.” (2020).

[9] Global Alliance for Incinerator Alternatives. "Plastics Exposed: How Waste Assessments and Brand Audits are Helping Philippine Cities Fight Plastic Pollution.” (2019).

[10] Zion Market Research. "Construction Aggregates Market by Product Type (Crushed Stones, Sand, Gravel, and Others) and by End-user (Residential, Commercial, and Industrial): Global Industry Perspective, Comprehensive Analysis, and Forecast, 2018-2025." (2018).

[11] Othman, Ayman M. "Effect of Low-Density Polyethylene on Fracture Toughness of Asphalt Concrete Mixtures." Journal of Materials in Civil Engineering 22, no. 10 (October 2010): 1019-1024. doi:10.1061/(asce)mt.1943-5533.0000106.

[12] Dalhat, M. A., Al-Adham, K., \& Habib, M. A. "Recycling of different plastics in asphalt concrete.” Use of Recycled Plastics in Eco-Efficient Concrete (2019): 287-305. doi:10.1016/b978-0-08-102676-2.00013-x.

[13] Vila-Cortavitarte, M., Lastra-González, P., Calzada-Pérez, M.A., \& Indacoechea-Vega, I. "The use of recycled plastic as partial replacement of bitumen in asphalt concrete." Use of Recycled Plastics in Eco-Efficient Concrete (2019): $327-347$. doi:10.1016/b978-0-08-102676-2.00015-3.

[14] Pacheco-Torgal, F., Jalali, S., \& Ding, Y. "Properties and durability of concrete containing polymeric wastes (tyre rubber and polyethylene terephthalate bottles): An overview." Construction and Building Materials 30 (2012): 714-724. doi:10.1016/j.conbuildmat.2011.11.047.

[15] Ismail, Z. Z., \& AL-Hashmi, E. A. "Use of waste plastic in concrete mixture as aggregate replacement." Waste Management, 28(11) (2008): 2041-2047. doi:10.1016/j.wasman.2007.08.023.

[16] Alqahtani, Fahad K., Gurmel Ghataora, Samir Dirar, M. Iqbal Khan, and Idrees Zafar. "Experimental Study to Investigate the Engineering and Durability Performance of Concrete Using Synthetic Aggregates." Construction and Building Materials 173 (June 2018): 350-358. doi:10.1016/j.conbuildmat.2018.04.018.

[17] Hameed, A. M., \& Fatah Ahmed, B. A. "Employment the plastic waste to produce the light weight concrete." Energy Procedia, 157 (2019): 30-38. doi:10.1016/j.egypro.2018.11.160.

[18] Mohammed, Azad A., Ilham I. Mohammed, and Shuaaib A. Mohammed. "Some Properties of Concrete with Plastic Aggregate Derived from Shredded PVC Sheets." Construction and Building Materials 201 (March 2019): $232-245$. doi:10.1016/j.conbuildmat.2018.12.145.

[19] Ashwini, M.B.T. "Partial replacement of E-plastic Waste as Coarse-aggregate in concrete." Procedia Environmental Sciences 35 (2016): 731-739. doi:10.1016/j.proenv.2016.07.079.

[20] Azhdarpour, A. M., Nikoudel, M. R., \& Taheri, M. "The effect of using polyethylene terephthalate particles on physical and strength-related properties of concrete; a laboratory evaluation." Construction and Building Materials 109 (2016): 55-62. doi:10.1016/j.conbuildmat.2016.01.056.

[21] Aldahdooh, M. A. A., Jamrah, A., Alnuaimi, A., Martini, M. I., Ahmed, M. S. R., \& Ahmed, A. S. R. "Influence of various plastics-waste aggregates on properties of normal concrete." Journal of Building Engineering, 17 (2018): 13-22. doi:10.1016/j.jobe.2018.01.014. 
[22] Devin, Austin, and P. Fanning. "Non-load bearing elements and their contribution to a structure's dynamic response." Experimental Vibration Analysis for Civil Engineering Structures (EVACES 2011), Lake Como, Italy (2011): 667-674.

[23]The Manila Times. "PH's first Eco brick hub." (2018). Available online: https://www.manilatimes.net/2018/09/05/business/real-estate-and-property/phs-first-ecobrick-hub/438185/.

[24] Green Antz Builders. "Eco-Bricks", Available online: http://www.greenantz.com/products.

[25] Rola, A.C. 2019. "Managing Plastic Waste and the Role of Local Governments." National Academy of Science and Technology Philippines (2019). Available online: https://www.nast.ph/index.php/downloads/category/151-sinlge-useplastics?download=632:3-rola-science-advisory-layout-b-191121.

[26] Lasco, Jonathan David, Marish Madlangbayan, and Marloe Baclayon Sundo. "Compressive Strength and Bulk Density of Concrete Hollow Blocks (CHB) with Polypropylene (PP) Pellets as Partial Replacement for Sand." Civil Engineering Journal 3, no. 10 (November 4, 2017): 821. doi:10.28991/cej-030917.

[27] Bayer, J., L.A. Granda, J.A. Méndez, M.A. Pèlach, F. Vilaseca, and P. Mutjé. "Cellulose Polymer Composites (WPC)." Advanced High Strength Natural Fibre Composites in Construction (2017): 115-139. doi:10.1016/b978-0-08-100411-1.00005-4.

[28] Brydson, J.A. "Plastics Materials, Seventh Edition". (1999). doi:10.1016/B978-075064132-6/50038-3.

[29] Jin, H., Gonzalez-Gutierrez, J., Oblak, P., Zupančič, B., \& Emri, I. "The effect of extensive mechanical recycling on the properties of low density polyethylene." Polymer Degradation and Stability, 97(11) (2012): 2262-2272. doi:10.1016/j.polymdegradstab.2012.07.039

[30] Chong, C. "Properties of Materials." (1977).

[31] American Society for Testing and Materials. "Standard Specification for Mixing Water Used in the Production of Hydraulic Cement Concrete, ASTM C1602.” Annual book of ASTM Standards (2006).

[32] American Concrete Institute. Committee 211. "Recommended practice for selecting proportions for normal and heavyweight concrete (ACI 211.1-77).” The Institute (1977).

[33] American Society for Testing and Materials. (2006). "Standard Test Methods for Sampling and Testing Concrete Masonry Units and Related Units, ASTM C140.” Annual book of ASTM Standards (2006).

[34] American Society for Testing and Materials. "Standard Test Method for Density, Relative Density (Specific Gravity), and Absorption of Coarse Aggregate, ASTM C127." Annual book of ASTM Standards (2006).

[35] Triantaphyllou, Evangelos. "Multi-Criteria Decision Making Methods: A Comparative Study.” Applied Optimization (2000). doi:10.1007/978-1-4757-3157-6.

[36] Ruiz-Herrero, J. L., Velasco Nieto, D., López-Gil, A., Arranz, A., Fernández, A., Lorenzana, A. Merino S., De Saja, J. A., Rodríguez-Pérez, M. Á. "Mechanical and thermal performance of concrete and mortar cellular materials containing plastic waste." Construction and Building Materials 104 (2016): 298-310. doi:10.1016/j.conbuildmat.2015.12.005.

[37] Saikia, N., \& de Brito, J. "Mechanical properties and abrasion behaviour of concrete containing shredded PET bottle waste as a partial substitution of natural aggregate." Construction and Building Materials 52 (2014): $236-244$. doi:10.1016/j.conbuildmat.2013.11.049.

[38] Safi, B., Saidi, M., Aboutaleb, D., \& Maallem, M. "The use of plastic waste as fine aggregate in the self-compacting mortars: Effect on physical and mechanical properties." Construction and Building Materials 43 (2013): 436-442. doi:10.1016/j.conbuildmat.2013.02.049.

[39] Ozyildirim, C. \& Carino, N. (2006). "Concrete strength testing." Significance of tests and properties of concrete and concretemaking materials (2006): 125-140.

[40] Jones, E. \& Childers, R. “Contemporary College Physics, Second Edition.” (1993).

[41] Matthews, F., \& Rawlings, R. “Composite Materials: Engineering and Science.” (1999).

[42] Mat Shayuti, M. S., Abdullah, M. Z., \& Megat Yusoff, P. S. M. "Compressive Properties and Morphology of Polypropylene/Polycarbonate Blends." International Proceedings of Chemical, Biological and Environmental Engineering 12 (2011) Conference on Environment and Industrial Innovation 12 (2011): 303-307.

[43] American Society for Testing and Materials. "Standard Specification for Non-Load-Bearing Concrete Masonry Units, ASTM C129." Annual book of ASTM standards (2006).

[44] Imai, H., Inoue, H., Minowa, C., Laniza, A.G., Penarubia, H.C., Narag, I.C., Solidum, R.J.U., Okazaki, K., Narafu, T., Sakuma, J., Kusunoki, J., Hanazato, T. "Shaking Table Experiment for Philippine Full-Scale.” Proceedings of the 15th World Conference on Earthquake Engineering (2012). 